\title{
Prognostic Factors in Operated T3-T4 Gastric Cancer
}

\author{
Orhan Uzun, Selçuk Gulmez, Aziz Serkan Senger, Aşkın Percem, Erdal Polat and Mustafa Duman \\ Department of Gastroenterological Surgery, University of Health Sciences, Kartal Kosuyolu Higher Specialty Training and Research \\ Hospital, Istanbul, Turkey
}

\begin{abstract}
Objective: To investigate the prognostic factors affecting survival in patients with a deep gastric wall invasion of T3-T4 advanced gastric cancer.

Study Design: Descriptive study.

Place and Duration of Study: Department of Gastroenterological Surgery, Kartal Koşuyolu High Specialty Training and Research Hospital, between November 2006 and December 2018.

Methodology: A retrospective review was made of 252 patients; and the clinicopathological characteristics and survival status in the presence of T1-T2 and T3-T4 patients were investigated. The cumulative survival of the two groups was analysed with a Kaplan-Meier test, and the differences were analysed with a log-rank test. The prognostic factors for T3-T4 patients were established through a stepwise Cox regression analysis.

Results: Of the total, $52(20.6 \%)$ patients had T1-T2 and 200 (79.4\%) had T3-T4 gastric wall invasion. Statistical differences were noted in the Lauren classification as gender, tumor size, presence of lymph node involvement, presence of vascular and perineural invasion, and overall survival $(p<0.001$ ). A univariate analysis of the prognostic factors affecting survival in T3-T4 patients revealed a difference in the tumor localisation, tumor size, the presence of involved lymph nodes, perineural invasion, and vascular invasion. A multivariate analysis of the prognostic factors affecting survival identified differences in tumor size, the presence of involved lymph nodes and perineural invasion.

Conclusion: The most significant prognostic factor affecting survival in patients with T3-T4 gastric cancer, based on the depth of gastric wall invasion, was the tumor size, lymph node involvement and perineural invasion.
\end{abstract}

Key Words: Advanced gastric cancer, Prognostic factor, Survival.

How to cite this article: Uzun O, Gulmez S, Senger AS, Percem A, Polat E, Duman M. Prognostic Factors in Operated T3-T4 Gastric Cancer. J Coll Physicians Surg Pak 2020; 30(10):1047-1052.

\section{INTRODUCTION}

Gastric cancer is the fifth most common of all cancer types, and the third most common cause of death from cancer worldwide. ${ }^{1}$ The diagnosis of gastric cancer is often delayed, meaning that patients often refer to their physicians with an advanced Tstage and with lymph node involvement, as the most significant prognostic factors. ${ }^{2}$ Early-stage gastric cancer is treated endoscopically or surgically, while curative resections and adequate lymphadenectomies following a multidisciplinary approach are recognised as the optimum surgical treatment method in the advanced stage. ${ }^{3}$ Furthermore, chemotherapy and/orchemoradiotherapy before or after surgical treatment is a standard treatmentapproach in the advanced stage. ${ }^{4}$

Correspondence to: Dr. Orhan Uzun, Department of Gastroenterological Surgery, University of Health Sciences, Kartal Kosuyolu Higher Specialty Training and Research Hospital, Istanbul, Turkey

E-mail: orhuzu@hotmail.com

Received: May 18, 2020; Revised: July 22, 2020;

Accepted: August 17, 2020

DOI: https://doi.org/10.29271/jcpsp.2020.10.1047
In the Japanese classification of gastric cancer, based on the depth of gastric wall invasion, T1 refers to the presence of invasion of the mucosa and/or submucosa; $\mathrm{T} 2$ indicates invasion of the muscularis propria; $\mathrm{T} 3$ refers to invasion of the subserosa; and T4 indicates invasion of the serosa and/or adjacent structures. ${ }^{5}$ In gastric cancer, $\mathrm{T} 1$ is referred to as early-stage gastric cancer, while $\mathrm{T} 2$ and above are considered advanced stage gastric cancer. ${ }^{5}$ Early-stage gastric cancer is cured at a rate of $\geq 90 \%$, while long-term survival rate is reported to be $30-50 \%$. This is despite the availability of neoadjuvant or adjuvant chemotherapy, and surgery and radiotherapy involving a multidisciplinary approach in cases of $\mathrm{T} 2$ and above; or in cases with lymph node involvement, with survival decreasing gradually. ${ }^{6}$

There are ongoing discussions about the role of adjuvant chemotherapy in T1 gastric cancer with lymph node involvement; and T2 gastric cancer without lymph node involvement, with suggestions that further studies are needed. ${ }^{7}$ Adjuvant chemotherapy is a standard approach in $\mathrm{T} 2$ gastric cancer with lymph node involvement and in T3 and above gastric cancer, regardless of lymph node involvement. ${ }^{7}$ There have been several studies examining the type of resection, lymph node involvement, venous invasion, perineural invasion, peritoneal cytology and tumor size, and the prognostic factors affecting survival in operated T3-T4 patients. ${ }^{8}$ 
Table I: Comparison of clinicopathological characteristics with the involvement of gastric wall layers (T1T2-T3T4).

\begin{tabular}{|c|c|c|c|c|c|}
\hline & \multicolumn{2}{|c|}{$\mathrm{T} 1, \mathrm{~T} 2(52)$} & \multicolumn{2}{|c|}{ T3,T4 (200) } & \multirow{2}{*}{$\mathbf{p}$} \\
\hline & $\mathbf{n}$ & $\%$ & $\mathbf{n}$ & $\%$ & \\
\hline $\begin{array}{l}\text { Gender: } \\
\text { M } \\
\text { F }\end{array}$ & $\begin{array}{l}29 \\
23\end{array}$ & $\begin{array}{l}55.8 \% \\
44.2 \%\end{array}$ & $\begin{array}{c}142 \\
58\end{array}$ & $\begin{array}{l}71.0 \% \\
29.0 \%\end{array}$ & $0.036 *$ \\
\hline $\begin{array}{l}\text { Lauren histological type: } \\
\text { Intestinal } \\
\text { Diffuse }\end{array}$ & $\begin{array}{l}27 \\
25\end{array}$ & $\begin{array}{l}51.9 \% \\
48.1 \%\end{array}$ & $\begin{array}{c}54 \\
146\end{array}$ & $\begin{array}{l}27.0 \% \\
73.0 \%\end{array}$ & $0.001^{* *}$ \\
\hline $\begin{array}{l}\text { Tumor diameter: } \\
\leq 4 \mathrm{~cm} \\
>4 \mathrm{~cm}\end{array}$ & $\begin{array}{l}34 \\
16 \\
\end{array}$ & $\begin{array}{l}68.0 \% \\
32.0 \% \\
\end{array}$ & $\begin{array}{c}71 \\
126\end{array}$ & $\begin{array}{l}36.0 \% \\
64.0 \%\end{array}$ & $<0.001^{* *}$ \\
\hline $\begin{array}{l}\text { Location: } \\
\text { Upper } \\
\text { Middle } \\
\text { Lower }\end{array}$ & $\begin{array}{l}11 \\
10 \\
31\end{array}$ & $\begin{array}{l}21.2 \% \\
19.2 \% \\
59.6 \%\end{array}$ & $\begin{array}{l}45 \\
59 \\
96\end{array}$ & $\begin{array}{l}22.5 \% \\
29.5 \% \\
48.0 \%\end{array}$ & 0.256 \\
\hline $\begin{array}{l}\text { Type of operation: } \\
\text { Subtotal } \\
\text { Total }\end{array}$ & $\begin{array}{l}32 \\
20\end{array}$ & $\begin{array}{l}61.5 \% \\
38.5 \%\end{array}$ & $\begin{array}{c}97 \\
103\end{array}$ & $\begin{array}{l}48.5 \% \\
51.5 \%\end{array}$ & 0.094 \\
\hline $\begin{array}{l}\text { Lymph node involvement: } \\
\text { No } \\
\text { Yes }\end{array}$ & $\begin{array}{l}42 \\
10\end{array}$ & $\begin{array}{l}80.8 \% \\
19.2 \%\end{array}$ & $\begin{array}{c}45 \\
155\end{array}$ & $\begin{array}{l}22.5 \% \\
77.5 \%\end{array}$ & $<0.001^{* *}$ \\
\hline $\begin{array}{l}\text { Vascular invasion: } \\
\text { Negative } \\
\text { Positive }\end{array}$ & $\begin{array}{l}37 \\
14\end{array}$ & $\begin{array}{l}72.5 \% \\
27.5 \%\end{array}$ & $\begin{array}{c}61 \\
139\end{array}$ & $\begin{array}{l}30.5 \% \\
69.5 \%\end{array}$ & $<0.001^{* *}$ \\
\hline $\begin{array}{l}\text { Perineural invasion: } \\
\text { Negative } \\
\text { Positive }\end{array}$ & $\begin{array}{l}39 \\
11\end{array}$ & $\begin{array}{l}78.0 \% \\
22.0 \%\end{array}$ & $\begin{array}{c}45 \\
155\end{array}$ & $\begin{array}{l}22.5 \% \\
77.5 \%\end{array}$ & $<0.001^{* *}$ \\
\hline $\begin{array}{l}\text { Complications: } \\
\text { No } \\
\text { Yes }\end{array}$ & $\begin{array}{l}40 \\
12\end{array}$ & $\begin{array}{l}76.9 \% \\
23.1 \%\end{array}$ & $\begin{array}{c}148 \\
52\end{array}$ & $\begin{array}{l}74.0 \% \\
26.0 \%\end{array}$ & 0.666 \\
\hline & Median & IQR & Median & IQR & $\mathbf{p}$ \\
\hline Age & 62 & $53-70$ & 62 & $53-68$ & 0.919 \\
\hline Number of lymph nodes removed & 23 & $16.25-34.5$ & 25 & $19-31$ & 0.248 \\
\hline Length of hospital stay & 10 & $8-14$ & 9 & $8-13$ & 0.876 \\
\hline
\end{tabular}

Table II: Comparison of survival by age, based on a Kaplan-Meier test.

\begin{tabular}{|l|l|l|l|l|}
\hline & Non-survivors & Survivors & $\begin{array}{l}\text { Estimate (median) } \\
\pm \mathbf{S E}\end{array}$ & $\mathbf{9 5 \% \mathbf { C l }}$ \\
\hline T1, T2 & $10(19.2 \%)$ & $42(80.8 \%)$ & $114.531 \pm 8.067$ & $(98.720-130.342)$ \\
\hline T3, T4 & $120(60.0 \%)$ & $80(40.0 \%)$ & $56.360 \pm 4.366$ & $(47.803-64.917)$ \\
\hline Overall & $130(51.6 \%)$ & $122(48.4 \%)$ & $69.004 \pm 4.277$ & $(60.622-77.387)$ \\
\hline$* * 0<0.001$. & & & & $<0.001 * *$ \\
\hline
\end{tabular}

However, these studies have included relatively low number of patient, and failed to assess the total number of lymph nodes removed.

The objective of the present study was to investigate the prognostic factors affecting survival of patients, who were operated at this Department for T3-T4 gastric cancer, based on the depth of tumor invasion; and compare the clinicopathological characteristics and surgical outcomes with those of patients with T1-T2 gastric cancer, based on the depth of tumor invasion.

\section{METHODOLOGY}

The records of a total of 320 patients with gastric adenocarcinomas, who underwent a total or subtotal gastrectomy and D2 lymph node dissection in the Department of Gastroenterological Surgery, Kartal Koşuyolu Higher Specialty Training and Research Hospital between November 2006 and December 2015 were analysed retrospectively. The cut-off date for the survival analysis was December 31, 2018. D2 dissections were performed in accordance with the principles of the Japanese Research Society for the Study of Gastric Cancer (JRSSG). ${ }^{5}$

Table III: Univariate and multivariate analyses of patients by T3-T4 stage. 


\begin{tabular}{|c|c|c|c|c|}
\hline & Univariate analysis & \multirow{2}{*}{$\mathbf{p}$} & Multivariate analysis & \multirow{2}{*}{$\mathbf{p}$} \\
\hline & OR $(95.0 \% \mathrm{Cl})$ & & OR $(95.0 \% \mathrm{Cl})$ & \\
\hline $\begin{array}{l}\text { Gender: } \\
\text { F } \\
\text { M }\end{array}$ & $0.767(0.523-1.122)$ & 0.172 & $1.025(0.670-1.567)$ & 0.910 \\
\hline Age & $1.007(0.993-1.021)$ & 0.353 & $1.000(0.984-1.017)$ & 0.958 \\
\hline $\begin{array}{l}\text { Localization: } \\
\text { Upper } \\
\text { Middle } \\
\text { Lower }\end{array}$ & $\begin{array}{l}1.651(0.994-2.742) \\
1.041(0.652-1.662)\end{array}$ & $\begin{array}{l}0.047 * \\
0.053 \\
0.866\end{array}$ & $\begin{array}{l}1.548(0.864-2.774) \\
1.603(0.481-5.338)\end{array}$ & $\begin{array}{l}0.338 \\
0.142 \\
0.442\end{array}$ \\
\hline Gastrectomy type & $1.272(0.901-1.797)$ & 0.172 & $1.678(0.559-5.043)$ & 0.356 \\
\hline $\begin{array}{l}\text { Lauren: } \\
\text { Intestinal } \\
\text { Diffuse }\end{array}$ & $1.344(0.918-1.968)$ & 0.129 & $1.001(0.662-1.514)$ & 0.996 \\
\hline $\begin{array}{l}\text { Tumor size: } \\
\leq 4 \mathrm{~cm} \\
>4 \mathrm{~cm}\end{array}$ & $2.100(1.431-3.081)$ & $<0.001^{* *}$ & $1.706(1.143-2.546)$ & 0.009* \\
\hline $\begin{array}{l}\text { The total number of removed lymph } \\
\text { nodes }\end{array}$ & $0.994(0.977-1.010)$ & 0.466 & $0.985(0.967-1.004)$ & 0.126 \\
\hline \begin{tabular}{|l|} 
Lymph node involvement: \\
No \\
Yes
\end{tabular} & $4.328(2.697-6.946)$ & $<0.001^{* *}$ & $3.345(1.880-5.954)$ & $<0.001^{* *}$ \\
\hline Vascular invasion & $2.208(1.500-3.249)$ & $<0.001^{* *}$ & $0.995(0.629-1.576)$ & 0.985 \\
\hline Perineural invasion & $2.679(1.728-4.154)$ & $<0.001^{* *}$ & $1.804(1.124-2.894)$ & $0.014 *$ \\
\hline
\end{tabular}

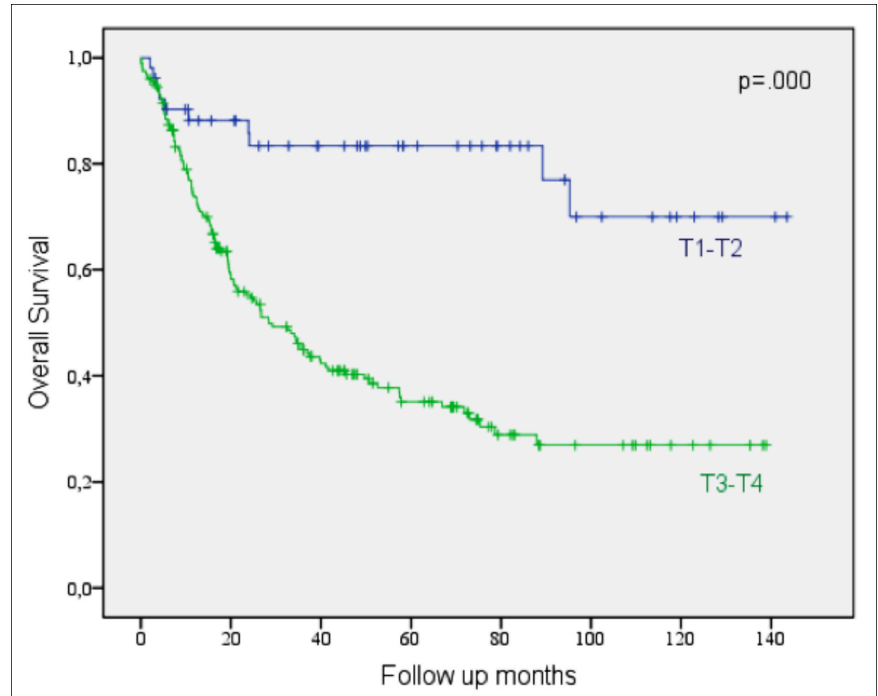

Figure 1: Comparison of overall survival of T1-T2 and T3-T4 stages.

The study made use of the tumor, node, metastasis (TNM) classification system of the American Joint Committee on Cancer (AJCC, 7th ed., 2010). The data were obtained from follow-up forms stored in this clinical database, and from the recorded pathology results. Patients diagnosed with distant organ metastasis at the time of surgery ( 8 patients), those with a positive peritoneal cytology (12 patients), those who underwent neoadjuvant chemoradiotherapy (34 patients), those with T3-T4 tumors with fewer than 15 lymph nodes removed (10 patients), and those with positive surgical margins (4 patients) were excluded from the study, even if they underwent a gastric resection. Subsequently, a total of 252 patients were included in the study. Complications occurring within 30 days of surgery were defined as being surgery-related, and were recorded.

The normality of the distribution of the numerical variables was evaluated with a Kolmogorov-Smirnov test, with median (IQR) values taken in the absence of a normal distribution when the $p$ value was less than 0.05 . Categorical variables were expressed as frequency and percentage. A Chi-square test, Fisher's exact test and Mann-Whitney U-test were used to analyse the differences in the study variables in comparison of patients with stage T3-T4 and those with stage T1-T2 invasion. A Kaplan-Meier test was used to compare the survival of T3-T4 and T1-T2 patients; and a log rank test was used to examine the differences between the survival curves. Univariate and multivariate analyses were performed with a stepwise Cox regression in order to identify the prognostic factors for survival in T3-T4 patients. The variables included gender, age, tumor localisation, gastrectomy type, Lauren classification of tumor size, total number of lymph nodes removed, status of lymph node involvement, vascular invasion, perineural invasion and presence of complications. SPSS version 21 software was used in the study, and the level of statistical significance was set at $p<0.05$.

\section{RESULTS}

The study included $52(20.6 \%)$ patients with T1-T2 stage invasion, and 200 (79.4\%) with T3-T4. A comparison of the clinicopathological characteristics of the two groups revealed no difference in age, tumor localisation, type of operation, total number of lymph nodes removed, presence of complications and length of hospital stay (Table I). There was a statistical difference between the genders of the two groups $(p=0.036)$, with $71 \%$ of the patients in the T3-T4 group being male, compared to $55.8 \%$ of the T1-T2 group. There was a statistical difference in the Lauren classification 
$(p=0.001)$, with $73 \%$ of the patients in the T3-T4 group having a diffuse histology, compared to $48.1 \%$ of the patients in the T1-T2 group. There was a statistical difference in the size of the tumors of the two groups $(p<0.001)$, with $64 \%$ of the patients in T3-T4 group having tumors greater that $4 \mathrm{~cm}$, while $68 \%$ of the patients in T1-T2 group having tumors smaller than $4 \mathrm{~cm}$. There was also a statistical difference recorded in lymph node involvement difference $(p<0.001)$. Lymph node involvement was identified in $77.5 \%$ of the patients in the T3-T4 group, compared to $19.2 \%$ of the patients in the T1-T2 group. A statistical difference was noted in the presence of vascular and perineural invasion; in the two groups $(p<0.001)$, with $69.5 \%$ and $77.5 \%$ of the T3-T4 group identified with vascular and perineural invasions, respectively. A comparison of the two patient groups revealed a statistical difference in survival ( $p<0.001$, Figure 1 ), with $40 \%$ and $80.8 \%$ of the T3-T4 and T1-T2 patients, respectively, surviving to the cut-off date (Table II). The prognostic factors for survival in the T3-T4 group were analysed using a Cox regression analysis (Table III). According to the univariate analysis, survival was affected 2.100 times with the tumor size larger than $4 \mathrm{~cm}$ $(p<0.001), 4.328$ times with the lymph node involvement $(p<0.001), 2.679$ times with the presence of perineural invasion $(p<0.001)$, and 2.208 times with the presence of vascular invasion $(p<0.001)$. A multivariate analysis revealed 1.706 times with the tumor size larger than $4 \mathrm{~cm}$ $(p=0.009), 3.345$ times with the lymph node involvement $(p<0.001)$, and 1.804 times with the presence of perineural invasion $(p=0.014)$.

\section{DISCUSSION}

For patients with gastric cancer of stage T2 and above, a D2 lymphadenectomy and gastrectomy are the standard approach, with chemotherapy administered before or after surgery. ${ }^{10}$ Despite all such efforts, T4 patients in particular tend to experience recurrence within the first five years. ${ }^{10}$ For T1-T2 stage gastric cancer, five-year survival is around $80-90 \%$, depending on the depth of tumor invasion; whereas, this rate decreases to $30-60 \%$ in the T3-T4 stages. ${ }^{2}$ Gastric cancer is usually not identified until it has reached an advanced T stage. A study by Yan Zhang et al. reported that patients identified with T1-T2-stage gastric cancer accounted for only $16 \%$ of the total, compared to $84 \%$ for those with T3-T4 stage. ${ }^{11}$ Sano et al. reported incidences of T1-T2 to account for $65-70 \%$ of the total, and T3-T4 to account for $30-35 \%$ in Asian countries like Japan and Korea, while reporting incidences of T1-T2 in $40-45 \%$ and T3-T4 in 55-60\% of cases in Western countries. ${ }^{5}$ The present study identified incidences of T1-T2 and T3-T4 of $20.6 \%$ and $79.4 \%$, respectively.

Several prognostic factors have been identified for gastric cancer, such as tumor invasion, lymph node metastasis, number of lymph node metastases, presence of distant metastasis, tumor size, macroscopic type, tumor localisa- tion, gender, age, presence of lymphovascular invasion and presence of perineural invasion. ${ }^{12,13}$ Furthermore, peritoneal cytology positivity and peritoneal cancer frequency have been reported to increase gradually in advanced T stages. ${ }^{14}$ The study by Qiu et al. reported a poor prognosis among patients with a Lauren diffuse histology; and suggested that the $T$ stage was more advanced and lymph node involvement was more common in this patient group. ${ }^{15}$ In the present study, a difference in the Lauren classification was noted also between the T1-T2 and T3-T4 groups, with more patients with a diffuse histology noted in the T3-T4 stages. The presence of such poor prognostic factors as nodal involvement, presence of lymphovascular invasion and presence of perineural invasion become more common as the $T$ stage advances, and such factors have negative effects on survival. ${ }^{16}$ In the present study, a statistical difference was noted in male gender, age, nodal involvement, presence of vascular invasion and perineural invasion, with poor prognostic factors being more common at advanced $T$ stages. There were also statistical differences between the two groups in terms of overall survival $(p<0.001)$.

Gastric cancer is rarely identified until it has progressed to the advanced stages. The primary treatment option in the early stage is endoscopy and/or surgery, while chemotherapy and/or radiotherapy is advised in addition to surgery in the advanced stages ${ }^{16}$ Although gastrectomy and D1 lymph node dissection are sufficient for patients undergoing surgery in the early T stages, D2 lymph node dissection has become the standard approach in the advanced $T$ stages. ${ }^{3}$ It has been reported that a minimum of 15 lymph nodes must be removed to ensure correct staging with D2 lymph node dissection. ${ }^{3}$ It has also been reported that increasing the number of lymph nodes removal has a positive impact on overall survival and reduces the rate of recurrence. ${ }^{17}$ The study by Zhao et al. reported that the number of lymph nodes removed was an important prognostic factor for T1N0 patients, with overall survival being positively affected by the removal of 15 or more lymph nodes. ${ }^{18}$ Xue et al. established that extensive lymph node dissection had a positive effect on survival in pathological T3-stage patients without lymph node dissection, but indicated poor prognosis in cases with upper-located tumors, of stage T3 and above when the tumor size was $>4 \mathrm{~cm}$ in patients aged over 65 years. ${ }^{19}$

D3 lymph node dissections can be performed safely and with low morbidity and mortality rates by experienced hands, although no contributing effect of increased survival has been established when compared to D2 lymph node dissection. ${ }^{20}$ The prognostic factors identified for T3-T4 include lymph node involvement, tumor size, peritoneal cytology positivity, advanced age, and the presence of lymphovascular and perineural invasion. ${ }^{21}$ In the present study, a univariate analysis revealed tumor localisation, tumor size greater than $4 \mathrm{~cm}$, lymph node involvement, and perineural 
and vascular invasion to be prognostic factors, with the most important prognostic factors being the size of the tumor being greater than $4 \mathrm{~cm}$, lymph node involvement and perineural invasion in a multivariate analysis.

The present study has some limitations, including its retrospective design, the low number of patients, the short follow-up period and the exclusion of patients with peritoneal involvement due to their limited number.

\section{CONCLUSION}

Gastric cancer is usually identified once it has reached the advanced $\mathrm{T}$ stages, given the lack of a national screening programme in our country. Today, neoadjuvant chemotherapy is still not a standard procedure for advanced T stages, in which the standard approach is D2 lymph node dissection along with gastrectomy. In the present study, the most important prognostic factors were found to be tumor size greater than $4 \mathrm{~cm}$, lymph node involvement, and perineural invasion in T3-T4 gastric cancer. Assessments through endoscopic and radiologic measurements of the tumor size can be convenient when the lymph node status cannot be identified through imaging modalities. Thus, the measurement of tumor size can be considered an evaluation method in terms of neoadjuvant therapy.

\section{ETHICAL APPROVAL:}

The study protocol was approved by the Ethics Committee of Kartal Koşuyolu Higher Specialty Training and Research Hospital, Ishtanbul, Turkey (Number: 2019.7/26-242). The study was conducted in accordance with the principles of the Helsinki Declaration.

\section{PATIENTS' CONSENT:}

A written informed consent was obtained from all participants.

\section{CONFLICT OF INTEREST:}

The authors declared no conflict of interest.

\section{FUNDING SOURCES:}

We state that no funding sources have supported the preparation and submission of this article.

\section{AUTHORS' CONTRIBUTION:}

OU, ASS, SG: Performed most of the study.

OU: Designed the study and analysed the data.

OU, AP: Wrote the manuscript.

$E P, A P, M D$ : Revised the manuscript.

OU, MD: Approved the final version of the manuscript.

\section{REFERENCES}

1. Bray F, Ferlay J, Soerjomataram I, Siegel RL, Torre LA, Jemal A. Global cancer statistics 2018: Globocan estimates of incidence and mortality worldwide for 36 cancers in 185 countries. CA Cancer J Clin 2018; 68(6):394-424. doi.org/ 10.3322/caac. 21492

2. Sano T, Coit DG, Ho Kim H, Roviello F, Kassab P, Wittekind
$C$, et al. Proposal of a new stage grouping of gastric cancer for TNM classification: International gastric cancer association staging project. Gastric Cancer 2017; 20(2):217-225. doi.org/10.1007/s10120-016-0601-9.

3. Randle RW, Swords DS, Levine EA, Fino NF, Squires MH, Poultsides $G$, et al. Optimal extent of lymphadenectomy for gastric adenocarcinoma: A 7-Institution study of the U.S. gastric cancer collaborative. J Surg Oncol 2016; 113(7): 750-5. doi.org/10.1002/jso.24227.

4. Wagner AD, Lordick F, Grabsch HI, Terashima M, Terada M, Yoshikawa $T$, et al. Multidisciplinary management of stage II-III gastric and gastro-oesophageal junction cancer. Eur J Cancer 2020; 124:67-76. doi.org/10.1016/j.ejca.2019. 09.006.

5. Kodera $Y$, Sano T. Japanese gastric cancer treatment guidelines 2014 (ver. 4). Gastric Cancer 2017; 20(1):1-19. doi.org/10.1007/s10120- 016-0622-4.

6. Reim D, Loos M, Vogl F, Novotny A, Schuster T, Langer R, et al. Prognostic implications of the seventh edition of the international union against cancer classification for patients with gastric cancer: The western experience of patients treated in a single-center european institution. J Clin Oncol 2013; 31(2):263-71. doi.org/10.1200/JCO.2012.44.4315.

7. Kim Y, Kim KM, Choi MG, Lee JH, Sohn TS, Bae JM, et al. Adjuvant chemotherapy with or without concurrent radiotherapy for patients with stage ib gastric cancer: A subgroup analysis of the adjuvant chemoradiotherapy in stomach tumors (ARTIST) phase III trial. J Gastric Cancer 2018; 18(4): 348-55. http://doi.org/10.5230/jgc.2018. 18.e34.

8. Aurello P, Berardi G, Tierno SM, Rampioni Vinciguerra GL, Socciarelli F, Laracca GG, et al. Influence of perineural invasion in predicting overall survival and disease-free survival in patients with locally advanced gastric cancer. Am J Surg 2017; 213(4):748-53. doi.org/10.1016/j.amjsurg.2016. 05.022 .

9. Zhao B, Huang X, Zhang J, Luo R, Lu H, Xu H, et al. Clinicopathologic factors associated with recurrence and long-term survival in node-negative advanced gastric cancer patients. Rev Esp Enferm Dig 2019; 111(2):111-20. doi.org/10. 17235/reed.2018.5829/2018.

10. Zhu B, Yuan S, Nie R, Li S, Yang L, Duan J. Prognostic factors and recurrence patterns in 44 gastric cancer patients after curative resection. J Cancer 2019; 10(5): 1181-8. doi.org/ 10.7150/jca.28993.

11. Zhang Y, Lu J, Du Y, Feng C, Wang L, Chen M. Prognostic value of neutrophil-to-lymphocyte ratio and platelet-to-lymphocyte ratio in gastric cancer. Med (Baltimore) 2018; 97(12):e0144. doi: 10.1097/MD.0000000000010144.

12. Wang HM, Huang CM, Zheng CH, Li P, Xie JW, Wang JB, et al. Tumor size as a prognostic factor in patients with advanced gastric cancer in the lower third of the stomach. World J Gastroenterol 2012; 18(38):5470-5. http://doi.org/ 10.3748/wjg.v18.i38.5470.

13. Jung YJ, Seo HS, Kim JH, Park CH, Lee HH. Cross-sectional location of gastric cancer affects the long-term survival of patients as tumor invasion deepens. Ann Surg Oncol 2017; 24(13):3947-53. http://doi.org/10.1245/s10434-017-61 $01-2$.

14. Higaki E, Yanagi S, Gotohda N, Kinoshita T, Kuwata T, 
Nagino $\mathrm{M}$, et al. Intraoperative peritoneal lavage cytology offers prognostic significance for gastric cancer patients with curative resection. Cancer Sci 2017; 108(5):978-86. http://doi.org/10.1111/cas.13219.

15. Qiu M, Cai M, Zhang D, Wang Z, Wang D, Li Y, et al. Clinicopathological characteristics and prognostic analysis of Lauren classification in gastric adenocarcinoma in China. J Transl Med 2013; 11:58. doi.org/10.1186/1479-5876- 11-58.

16. Imamura $\mathrm{T}$, Komatsu S, Ichikawa D, Kubota T, Okamoto K, Konishi $\mathrm{H}$, et al. Poor prognostic subgroup in T3NO stage IIA gastric cancer, suggesting an indication for adjuvant chemotherapy. J Surg Oncol 2015; 111(2):221-5. http:// doi.org/10.1002/jso.23796.

17. Zheng WF, Ji TT, Lin Y, Li RZ. The prognostic value of lymph nodes count on survival of patients with node-negative gastric cancer. Oncotarget 2016; 7(28):43680-8. doi: 10.18632/oncotarget.9845.
18. Zhao J, Du F, Zhang Y, Kan J, Dong L, Shen G, et al. Impact on long-term survival of the number of lymph nodes resected in patients with pT1N0 gastric cancer after R0 resection A multicenter study in China. Med (Baltimore) 2016; 95(31):e4420. doi.org/10.1097/MD.0000000000 004420 .

19. Xue Q, Wang XN, Deng JY, Zhang RP, Liang H. Effects of extended lymphadenectomy and postoperative chemotherapy on node-negative gastric cancer. World J Gastroenterol 2013; 19(33):5551-6. doi.org/10. 3748/wjg. v19.i33.5551.

20. Douridas GN, Pierrakakis SK. Is there any role for D3 lymphadenectomy in gastric cancer? Front Surg 2018; 5:1-7. doi.org/10.3389/fsurg.2018.00027.

21. Fukuda N, Sugiyama Y, Wada J. Prognostic factors of T4 gastric cancer patients undergoing potentially curative resection. World J Gastroenterol 2011; 17(9):1180-4. doi.org/10.3748/wjg.v17.i9.1180. 